\title{
New Methods for Reducing the Problems of Photovoltaic Systems
}

\author{
Sobhan Dorahaki \\ Young Researchers and Elite Club, Bushehr branch, Islamic Azad University, Bushehr, Iran \\ email: sobhandorahaki@gmail.com
}

\begin{abstract}
Increasing of demand in the energy sphere and also unprecedented proliferation of environmental pollutants in the air has pushed human toward the using of renewable energy sources such as photovoltaic systems. Unfortunately, despite all the efforts made, in the field of photovoltaic systems, still the usability of this clean and renewable source is skeptical in the world. This paper examines some basic problems of photovoltaic systems and discusses a few new approaches to reduce some problems of photovoltaic systems. The proposed approaches have capabilities and difficulties which are investigated in this study.
\end{abstract}

Keywords: photovoltaic-New Method -Hovering-solar tree-sea

Copyright $₫ 2015$ Institute of Advanced Engineering and Science. All rights reserved.

\section{Introduction}

One of the methods which has been proposed to reduce the environmental issues is the use of photovoltaic systems as a source of clean and renewable energy [1-3]. Nowadays following the increasing demand in the energy sphere, many people across the world have benefited from solar technologies and consistently has been added on the number of panels installed all over the world [4]. One reason for using this energy can be its easy usability (compared with wind power stations). It can be said that photovoltaic industry in the world has the capacity of more than $40 \mathrm{GW}$ in the energy production of the world [5]. Photovoltaic systems are commonly used in two forms of connected or disconnected from the network. Usually disconnected from of network can be helpful in remote areas of the network which the cost of electricity is high for them $[6,7]$. Below are mentioned some locations which commonly use photovoltaic power systems:

1) Construction purposes in the urban construction

2) Tourism locations in remote areas of the network

3) Establishing power plants

4) Agricultural lands as a power supply

Generally the field of solar system can be considered widespread, as the purposes mentioned above only express a small part of the exploitation of solar panels. Photovoltaic systems, along with all the benefits that have for power network also consistently have some problems, which these issues always reduce the amount of using them. Researchers are always looking to provide new and innovative methods to reduce the problems of such systems. Since solar panels consistently require a large area for solar energy harvesting, one of the problems that solar systems are facing is the problem of required land area. This problem mostly shows itself in power plant purposes, because building a power plant practically takes an area of few acres without any usability (agricultural, construction, etc.). Another problem that photovoltaic systems are often facing is excessive warming of the panel's problem. This problem is observable in reducing the useful life of the panels and also reducing the systems efficiency with considering of $P_{-} V$ and $I \_V$ arrays in a variable temperature [8]. Figure 1 indicates amount of reduction in the output power of panel in the variable temperature. 


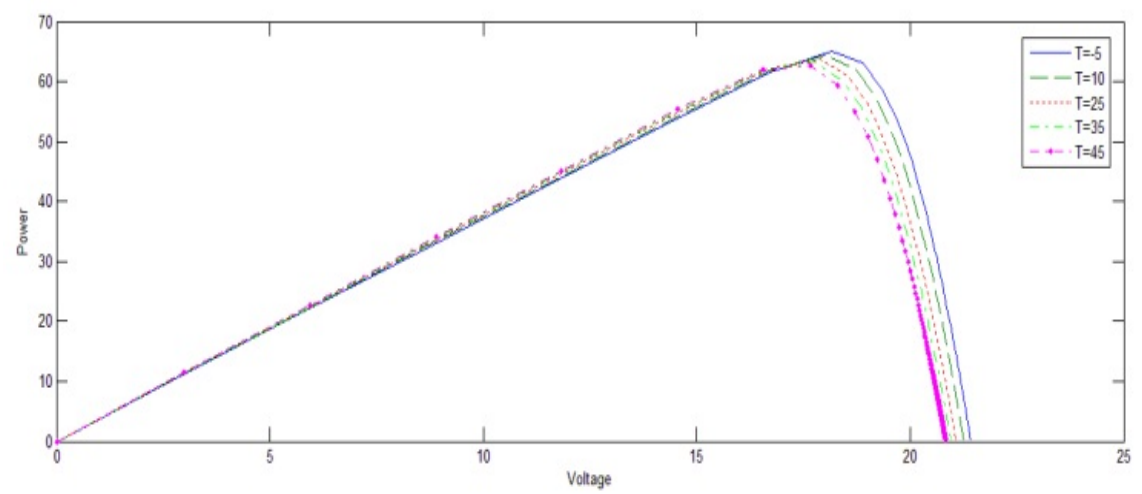

Figure 1. $P_{-} \vee$ diagram for constant exposure of $1 \mathrm{~kW} / \mathrm{m}^{\wedge} 2$ and a change in temperature of $5^{\circ} \mathrm{C}$ to $45^{\circ} \mathrm{C}$

The other influential problem in this field, is the problem of drop shadow effect on the solar panel. Due to the direct relation between amounts of exposure received by the panels and amount of solar electricity generated output, drop shadow is described as a destructive factor $[9,10]$. In this paper through proposing of new installation locations, innovative methods to alleviate the above mentioned problems are presented.

\section{The Simulation Of Photovoltaic Systems Based On Physical Behavior}

The physical behavior of a photovoltaic cell is very similar to a diode with a P-N link. By radiating to a link, some energy penetrate into the link and reaches to its P-N link. This causes that the current creates in the semiconductor. In ideal cells, the wasted current amount is zero. But in reality, some amount of generated current is wasting. Usually the wasted current with a parallel resistance $\left(R_{s i}\right)$ are placed in connection with ground. This resistor value is usually a large number. Because in usual, the wasted amount is much lower than the output value. By applying the above contents, Figure 2 circuit is resulted.

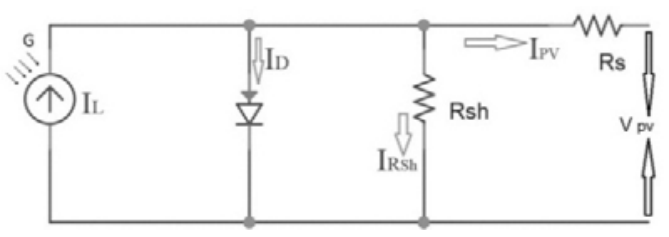

Figure 2. Circuit model of a photovoltaic system [11]

Current source shown in Figure 2 is a modeling of a produced current that its amount is based on temperature and environment radiation values [12]. Equation (1) shows its value.

$$
I_{l}=\frac{v}{G_{m}}\left(I_{m n}+K_{l}\left(T-T_{n}\right)\right)
$$

In above equation, $G$ is actual radiation, $G_{n}$ shows reference radiation, $T_{n}$ shows reference temperature, $I_{s m}$ is short circuit current in $T_{n n}, G_{n}$ condition and $K_{i}$ is current increased coefficient for the variations per each Celsius degree. As described above, $R_{s h}$ that shown in Figure 2 represents a path for leakage current $I_{l}$ to ground. The current amount is obtained through the Equation (2):

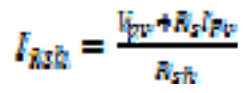


In above equation, $I_{p v}$ panel output current and $V_{p v}$ is output voltage. The current and voltage output amount are largely dependent on load resistance value. The output voltage is largely a non-linear component which this reason should search in diode non-linear (exponential) functions. The $I_{B}$ current value can be obtained from Equation (3):

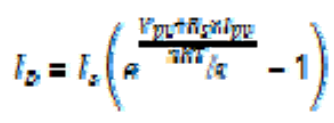

Also we can apply $\mathrm{KCL}$ rule at the top node, output current relation obtained in the following way:

$$
I_{p v}=I_{l}-I_{D}-I_{R S \mathrm{I}}
$$

\section{Hovering Photovoltaic System}

Generally one of the major problems in the construction of any power plant is the problem of required area for the project. This problem in crowded urban areas can dissuade energy field investor from doing the project. Also creating of solar buildings (panel installation on the roof of the building), due to limited space and low efficiency of panels, entails the problem of power produced shortage required for the domestic use. Another problem is the issue of drop shadow that as described in the previous section, have an adverse effects on the panel. One of the proposed solutions for overcoming the above problems is by using hovering systems. In this respect, some balloons can considered which are fixed to the ground through connecting cables and held photovoltaic panels hovering. Cable holders have the duty of transferring power generated in the land as well as fixing balloons. In Figure 2 an example of a hovering photovoltaic system is shown.

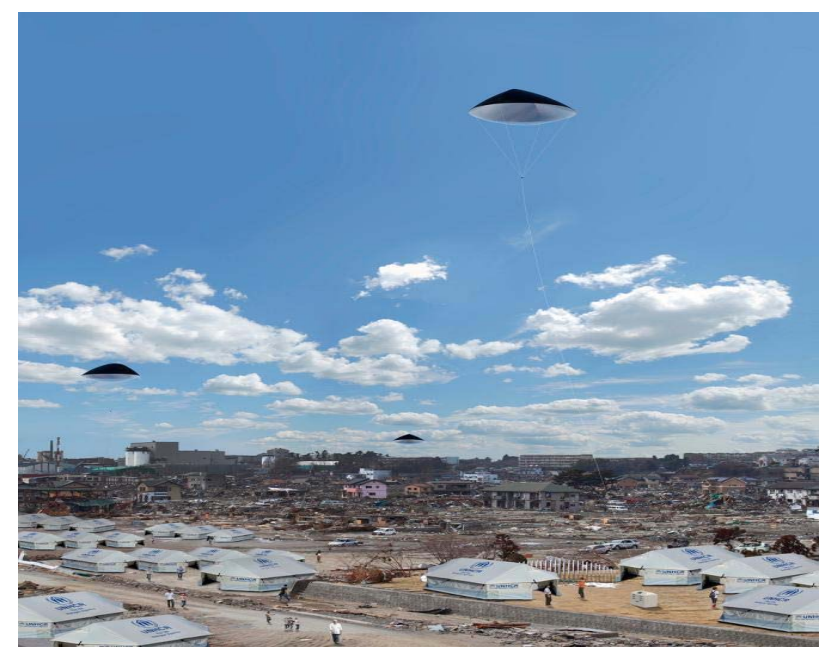

Figure 2. Example of hovering photovoltaic systems

The above method based on eliminating the need for land area is considered as an effective step in order to reduce the cost of photovoltaic systems. Also the use of hovering photovoltaic system's balloons can reduce the possibility of drop shadow from the objects compared with panels' installation on the ground level. In this project along with the photovoltaic system, wind turbines can also be placed and establish a hybrid photovoltaic - wind hovering which according to the enormous speed of the wind in sky compared to the ground level, can be an effective method.

From problems of this approach, the possibility of connector cable rupture and the cost of establishing balloons, can be noted. 


\section{Installation of Photovoltaic System in Transmission Lines}

Another proposed method of non-allocating specific land area for photovoltaic power plant is installation of photovoltaic panels in the transmission cable. This method can also be an effective manner of reducing the drop shadow effect on the photovoltaic systems and also removal of land area parameter for the photovoltaic power plant projects. Figure 3 shows an example of photovoltaic panels installed on the transmission cables.

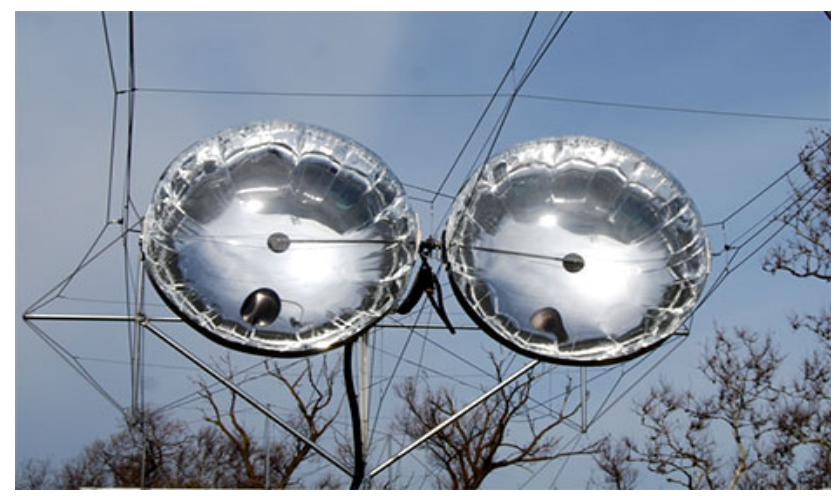

Figure 3. Photovoltaic panels installed on transmission lines

Of problems this design, weight gaining of transmission lines and the need for insulators that can withstand the mentioned weight, can be named. It is clear that the prices of these insulator is more expensive compared to conventional insulators and would be effective on the ultimate cost of the project. The wind factor also can be effective in this project.

\section{Solar Tree}

Another idea to use the photovoltaic systems is in the form of solar trees creation in the city. This artificial trees which their leaves are the solar panels, can be used as a platform for mobile charging of passengers on the roadsides, parks and also will create a shadow or a place to relax or car parking. In Figure 4 an example of this solar trees is shown. Due to the simplicity and applicability of this method, no certain defects was observed in this study for this method.

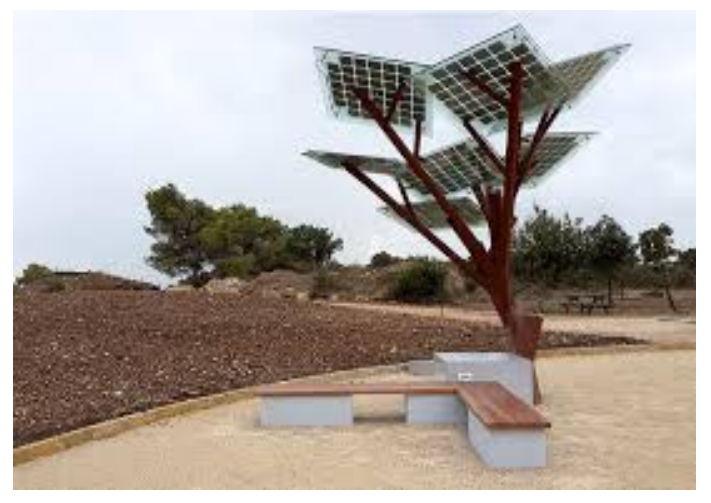

Figure 4. Example of a solar tree

\section{Installation of Potovoltaic Ssystem in Sea Surface}

One of the proposed solutions for three issues of required land area, drop shadow and high temperature which are the major problems of photovoltaic systems is installation of photovoltaic panels in sea level. By doing so, not only the surface of the earth will not be 
occupied, but the pages placed on the surface of water can be used as a bridge on the water surface. It is also clear that at sea levels, probability of drop shadow is much less compared to land surface. Also this approach can lessen increasing temperature of panels and thus reducing the output power of panels by using the mechanism of sea water and properties of water heat absorption. Figure 5 indicates an example of a photovoltaic power plant in sea level. Of problems of this method, environmental problems for fisheries and destruction of the beaches' natural environment may be named.

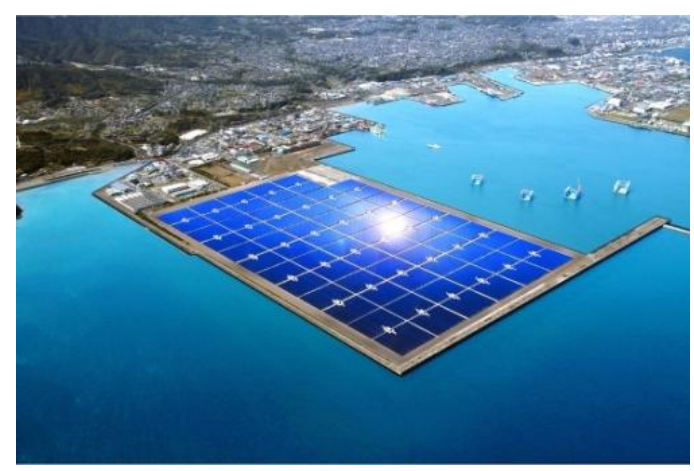

Figure 5. An example of a photovoltaic power plant in sea level

\section{Conclusion}

According to this study, considering the problems of land shortage, drop shadow effect of buildings and objects adjacent to panels, need to determine modern locations and methods for extracting energy from photovoltaic systems is undeniable. In this study, Innovative methods for using photovoltaic systems was explained. Also in each section along with the advantages of each method, disadvantages were also described. It can be said that for parks, parking lots and in general municipal purposes, the best approach is using of solar trees and also as large-scale power plant they can be used with the above types of improved structure.

This paper can be used in creation of low-cost power plants and economical photovoltaic. In this study, new methods for optimal use of photovoltaic systems was presented as a proposal and advantages and disadvantages of them were examined. In future studies, more detailed study for optimization of mentioned techniques is recommended.

\section{References}

[1] T Esram, PL Chapman. Comparison of Photovoltaic Array Maximum Power Point Tracking Techniques. IEEE Transactions on Energy Conversion. 2007; 22(2): 439-449.

[2] Awang Bin Jusoh, et al,. Variable Step Size Perturb and Observe MPPT for PV Solar Applications. TELKOMNIKA Telecommunication, Computing, Electronics and Control. 2013; 13(1): 1-12.

[3] JB Fulzele, S Dutt. Optimium Planning of Hybrid Renewable Energy System Using HOMER. International Journal of Power Electronics and Drive Systems (IJPEDS). 2012; 2(1).

[4] S Dorahaki. Evaluating the Radiation and Temperature Effect on Photovoltaic Systems. Bulletin of Electrical Engineering and Informatics. 2015; 4(1): 1-6.

[5] K Thanapalan, F Zhang, S Carr, G Premier, A Guwy, J Maddy. An overview of renewable energy technologies and hydrogen economy. Renewable Energy and Power Quality Journal. 2013; 1(11): 322.

[6] NHA Rahman, AM Omar. Modeling of a maximum power point tracker for a stand-alone photovoltaic system using MATLAB/Simulink. Int. J. Low-Carbon Tech. 2012: 1-7.

[7] G Dharmireddy, et al. A Voltage Controller in Photo-Voltaic System with Battery Storage for StandAlone Applications. International Journal of Power Electronics and Drive Systems (IJPEDS). 2012; 2(1).

[8] S Dorahaki. A Survey on Maximum Power Point Tracking Methods in Photovoltaic Power Systems. Bulletin of Electrical Engineering and Informatics. 2015; 4(3): 446.

[9] $V$ Quaschning, R Hanitsch. Numerical simulation of current-voltage characteristics of photovoltaic systems with shaded solar cells. Solar Energy. 1998; 56(6). 
[10] SH Niranjan Deshkar, et al. Solar PV array reconfiguration under partial shading conditions for maximum power extraction using genetic algorithm. Renewable and Sustainable Energy Reviews. 2015; 43(3). doi:10.1016/j.rser.2014.10.098

[11] H Patel, V Agarval. Matlab based Modeling to Study the Effects of Partial Shading on P $V$ Array Characteristics. IEEE Trans. on Energy Conversion. 2008; 23(1): 302-310. DOI: 10.1109/TEC.2007.914308

[12] C Keles, et al. A Photovoltaic system Model for Matlab/Simulink simulation. Power Engineering, Energy and Electrical Drives (POWERENG), Fourth International Conference 2013: 1643-1647.

TELKOMNIKA Vol. 16, No. 1, October 2015: 13 - 18 